\title{
A Review on the Acoustical Properties of Natural and Synthetic Noise Absorbents
}

\author{
Mohammad Reza Ghotbi Ravandi'1, Hossein Mardi', Ali Akbar Alinaghi Langari', \\ Mostafa Mohammadian'2, Narges Khanjani ${ }^{3}$ \\ ${ }^{1}$ Department of Occupational Health Engineering, School of Public Health, Kerman University of Medical \\ Science, Kerman, Iran \\ ${ }^{2}$ Occupational Health Engineering, Jiroft University of Medical Sciences, Jiroft, Iran \\ ${ }^{3}$ Department of Biostatistics and Epidemiology, School of Public Health, Kerman University of \\ Medical Science, Kerman, Iran \\ Email: $\underline{n}$ khanjani@kmu.ac.ir
}

Received 15 July 2015; accepted 31 July 2015; published 5 August 2015

Copyright (C) 2015 by authors and OALib.

This work is licensed under the Creative Commons Attribution International License (CC BY).

http://creativecommons.org/licenses/by/4.0/

(c) (i) Open Access

\section{Abstract}

Background and aims: Nowadays, artificial insulators such as fiberglass and rock wool are used as sound absorbers in developing countries. The present study is performed to introduce new sound absorbing materials used in developed countries and discuss their acoustical characteristics. It also aims to look at the efficiency of sound absorber natural materials (green materials) as an alternative to commercial materials with a synthetic base used in different places. Methods: In order to identify new porous absorbents, their mechanism of action and various applications, a search was conducted by using keywords such as "Sound Absorbent", "Natural Noise Absorbent" and "Passive Absorber" in PubMed, Scopus, Science Direct, ProQuest, Springer, Web of Knowledge, Magiran, SID, IranMedex and Google Scholar. We selected 48 review and original research papers that were about natural and recycled absorbents. Results: Most recent research includes production and optimization of sound absorbers using natural and recycled materials. The aim of all of these researches was producing green absorber materials in accordance with environmental regulations. In order to properly use these materials, in addition to knowing the benefits and suitability of absorbers for use in the intended environment, the effective factors in sound absorption such as fiber size, air flow resistance, porosity, curve, thickness and density of absorbers were considered. Conclusion: In comparison to old absorbents, new materials are safer and lighter and enjoy a more efficient technology. It seems like environmental friendly, degradable, recyclable and green noise absorbents will play on important role in the market of noise absorbents in the future. Also because of the place and different uses of absorbent materials, specialists should consider the limitations of the environment and the acoustic characteristics of the absorbents.

\section{Keywords}

Sound Absorbing Material, Natural, Environmentally Friendly

How to cite this paper: Ghotbi Ravandi, M.R., Mardi, H., Langari, A.A.A., Mohammadian, M. and Khanjani, N. (2015) A Review on the Acoustical Properties of Natural and Synthetic Noise Absorbents. Open Access Library Journal, 2: e1598. 


\section{Subject Areas: Environmental Sciences}

\section{Introduction}

The word acoustic is form a Greek word which means hearing and acoustics means the science of sound and is about the production, dissemination, transmission and control of sound. Sound and vibration are the harmful side effects of many mechanical systems such as home appliances, motor vehicles and buildings [1]-[4]. In residential and commercial places according to the regulations, the maximum noise threshold has been determined and if noise exceeds this limit, it threatens the comfort and health of the residents. Therefore, noise isolation in buildings is necessary. The sources of noise and vibration are recognizable. Noise and vibration from machines can be controlled by isolating vibration, using obstructers and noise absorbents. Absorbents are light weighted and can control noise appropriately and have a wide application in the construction of airplanes, rockets and ships. These materials are an appropriate replacement to compensate for the soaring demands for increasing loading capacity and decrease in petrol consumption in machines, trucks and rockets [4]. Proper design of acoustic and vibration systems can be performed through various methods such as Statistical Energy Analysis (SEA) [5]. In the last 50 years the application and variety of specific absorbent material has noticeably increased. The main reason for this was both advances in technology and general anxiety about the harmful effects of noise in our everyday life. In 1970 worrisome about public health led to changes in the main absorbent material from asbestos to other artificial fibers. These new fibers can provide more safety for human health. Recently, the dissemination of greenhouse gases by industries in the atmosphere has led to global warming and has changed the marketing of acoustic material. Industries and transportation have directly and indirectly led to the dissemination of $\mathrm{CO}_{2}, \mathrm{CH}_{4}$ and $\mathrm{NO}_{\mathrm{x}}$. The dissemination of these gases directly and indirectly is related to these industries. Therefore public perception and worrisome about the negative effect of these contaminants, has directed producers toward providing environment friendly products, with less polluting processes and in other words green products. Therefore increasing research on acoustic material and reviewing the available literature seems necessary and crucial [6] [7]. Recent scientific progress in metallurgy, chemistry and nanotechnology has led to enormous improvements in design, production and efficiency of acoustic material. This progress includes production and application of natural fibers such as bamboo fibers [8], flax [9], rice straw [10], coconut fibers [11], bio polymers, recycled material and waste such as paper waste [12], disposed tires [13], egg cartoons [14], spongeous metals, new composites and decorating material.

Currently in Iran heat insulators such as fiberglass and rock wool have been used as noise absorbers, but they have cons such as health risks, polluting working places and the environment by factories producing non-polymer absorbents, the presence of metal oxides in their chemical structure and their high water absorbing capability and high density which leads to unstable noise absorbing properties [15] [16]. Architects and acoustic engineers have now a wide range of noise absorbing material to select from, which not only secure the acoustic characteristics they want, but also provide a wide range of colors, shapes, sizes, weights, fire stages and assembly methods [17].

In this paper, the available literatures about sound absorbents have been collected in order to introduce the newest applicable porous noise absorbents in developing countries, and also to describe their acoustic characteristics and proper application. Also in this study we intend to compare the absorbing coefficient of natural absorbents, absorbents from recycled material and absorbents made from synthetic material in Iran.

\section{Methods}

English and Persian databases include PubMed, Scopus, Science Direct, ProQuest, Springer, Web of Knowledge, Magiran, SID, and Iranmedex and Google Scholar and we searched until July 2012 by keywords such as "Sound Absorbent", "Natural Noise Absorbent" and "Passive Absorber". Forty eight review and original research papers about natural and recycled absorbents were retrieved and used in this article.

\section{Results}

Most recent research includes methods for production and optimization of sound absorbers using natural and 
recycled material. The aim of all of this research was producing green absorber material in accordance with environmental regulations. In order to properly use these materials, in addition to knowing the benefits and suitability of absorbers for use in the intended environments, the effective factors in sound absorption such as fiber size, air flow resistance, porosity, curve, thickness and density of absorbers were considered.

\subsection{Porous Absorbents}

There is a wide range of natural noise absorbents. They secure all absorbent characteristic such as frequency, combination, thickness, finish and surveillance methods. On the other side, materials that have high absorbent properties are usually porous [4] [17]. Porous noise absorbers are materials with tiny pores, ridges or holes, in which noise waves can enter through them. These materials are classified according to their accessibility to foreign media such as air. Figure 1 shows a schematic view of a porous absorbent. Pores which are completely separate from adjacent pores are called closed pores. These pores have effects on some of the macroscopic characteristic of material such as density, mechanical strength and thermal conductivity. Closed pores have a lower efficiency than open pores in absorbing sound energy. Also open pores have long ridges parallel to the external surface of the material which has a noticeable effect on sound absorbing. Open pores can also exist as one ridge (only one side open) or overall pores (both ends open) [4].

Porous absorbent materials are classified into cellular, fibrous and granular absorbents. This classification is done according to the macroscopic structure of material. Polyurethane absorbing material and foams made from open porous cellular material are examples of porous absorbing cellular material. Fibrous absorbent material includes a number of porous tunnel shape material, which are made by the space between the available fibers in the materials. The fibers which make them include natural and artificial fibers such as mineral and glass fibers [4] [18]. Granular absorbent material includes relatively hard and macroscopic granules, in which their internal empty spaces have been filled with big bubbles (mineral cartridge).Other granular material includes solid, light and slippery material, which are shaped with other special material in the form of condensed blocks. Granular absorbent material also includes some forms of asphalt, porous concrete, granular clay, sands and soil [19] [20] [21]. Figure 2 shows the three main types of porous absorbents, their microscopic structure and some of the physical models used as mechanisms of sound absorption in these materials [4].

\subsection{Fibrous Porous Material}

Most of the porous sound absorbing materials are fibrous. Fibrous materials are made from long strings in which air is trapped in between. They are made in the shape of rings or layers with different mechanical acoustic or thermal characteristics. Fibers are classified as natural and artificial. Natural fibers can be from plants (cotton, hemp, cannabis, flax, wood, etc.), animals (wool, skin) or mineral (asbestos) origin. Artificial fibers include cellulose

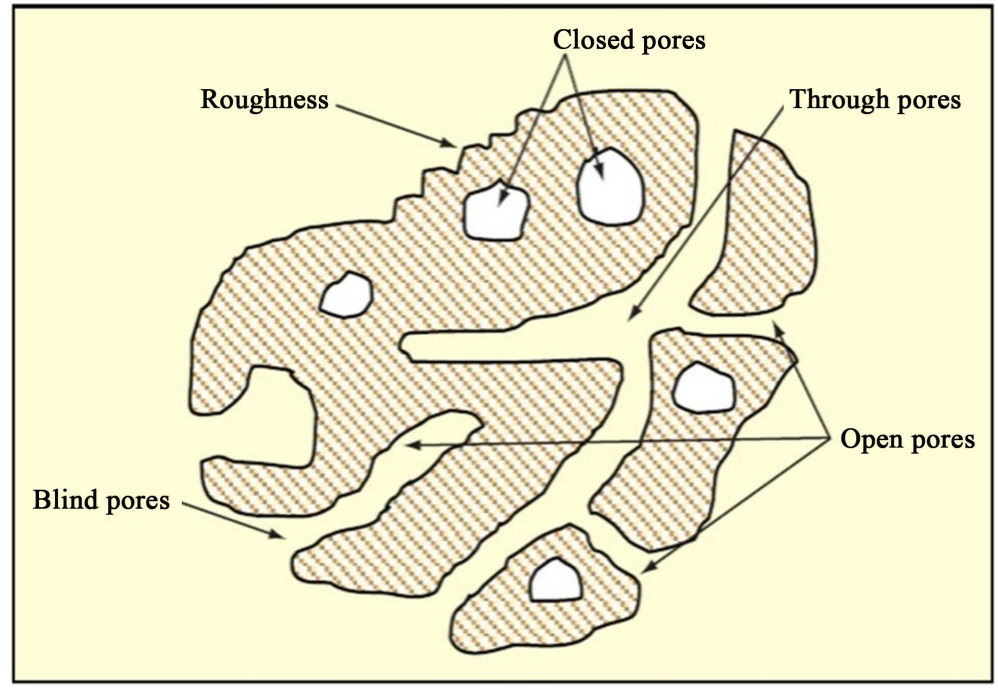

Figure 1. The cross-sectional view of solid porous material (taken from Ref. 4). 

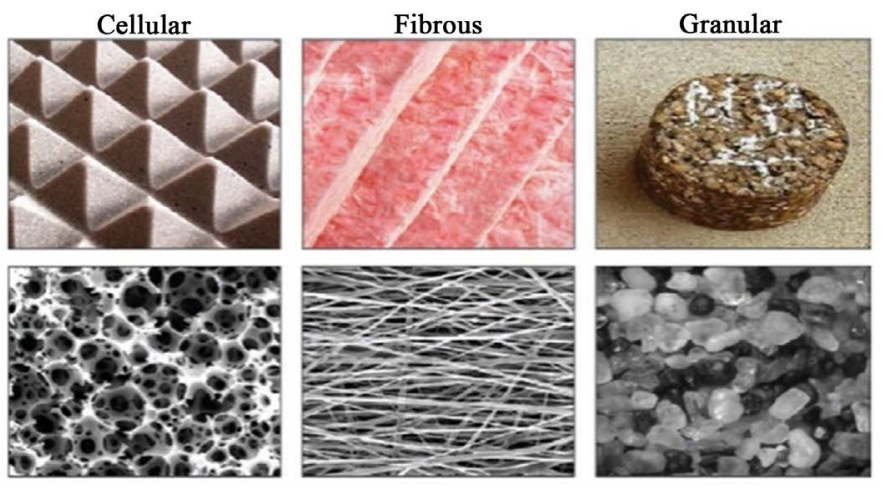

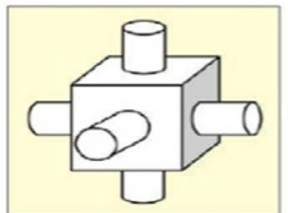

Cubic cells with connecting pores

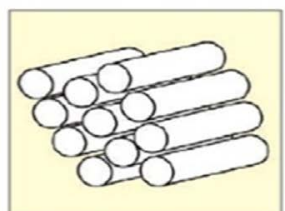

Parallel fiber bundles Stacked identical sperhes

Figure 2. The three main types of porous absorbent material. From left to right: 1-Cellular, cubic cells with connecting pores; 2-Fibrous, parallel fiber bundles; 3-Granular, stacked identical spheres (taken from Reference 4).

(bamboo fibers), minerals (fiber glass, mineral wool, wool glass, graphite, ceramic, etc.) or polymers (polyester, poly propylene, Kevlar, etc.) [4]. Artificial fibers are made from mineral and polymers which are used for sound absorption and heat control. They are built through high temperature and according to industrial processes on artificial chemicals and are produced from petrochemical material, therefore the presence of carbon is obvious in these material. Recently the application of natural fibers in producing sound absorbing material has attracted attention [22]-[25]. Natural fibers are produced completely under biodegradable and modern techniques and through environmental friendly procedures.

Cannabis is one of the important natural fibers. Cannabis is produced without the necessity of using chemicals. Also the production of cannabis fibers in one square meter is much more in comparison to cotton and flax. Also they need less water for growth. Cannabis fibers are naturally antimicrobial and resistant to ultra violet radiation, fungus, moulds and insects. Each of these characteristic makes their use in isolating sound in open places, possible. Flax is another plant which is from the cotton family. Its fibers are used to strengthen concrete and other composites in the construction process and in the automobile industry. The material used for thermal isolation and sound absorption are a mix of natural flax fibers, polyester fibers for strengthening and anti fire products which are available in the material (4). Therefore they are proper substitutes for material with chemical, polymer or other harmful artificial material.

\subsection{Metal, Ceramic and Jelly Foam Absorbents}

Polyurethane foams and melamine porous absorbents are cellular. These foams are used for environments in which thermal and corrosive resistance is important. Metal foams are relatively new material which are used specifically for producing light structures, medical cultures, filters, heat converts, sound absorbers and mechanical adjusting equipment [4] [25]. Aluminum foams are more popular among metal foams. Currently the use of new raw material such as Nickel, Steel, Titanium and Copper for the production of these foams has begun [26] [27]. Miushi et al. have studied the efficacy of sound absorption in aluminum foams named Alporas, currently these foams have been used successfully in noise control of highways and urban bridges in Japan [28]. Metal foams have advantages such as high strength, light weight, resistance to fire and low humidity absorption. Metal foams are usually expensive, but are recyclable. According to this process, foams can be porous open or closed cells. Open cellular foams can be produced by polyurethane foams as the base matrix [29]. Metal foam has a porous index between 75 to 95 percent [26].

Closed cellular material do not absorb noise properly, however the noise absorption property of these metal foams can be increased by folding or making holes by drilling. Folding makes the surface of some cells to crack 
and sharp ridges appear. Therefore, noise absorption can happen by viscous passage in the ridges due to thermo elastic degradation and cellular reactions known as Helmholmse [30]. Usually, metal foams are good noise absorbers for low frequencies between 1 to $5 \mathrm{kHz}$. Also metal foams have some of the advantages of an independent absorbent used for thermal control and hard working conditions [31]. Meanwhile efficient noise absorption can be achieved by putting metal foam in an appropriate distance from an impermeable wall. An important note about metal foams is the fact that these materials have a very good potential for vibration control, because [4]:

- The capacity of metal foams is higher than solid metals and with a factor more than 10.

- Panel foams in vibration frequency changes have more flexibility in comparison to solid layers and in the same unit of mass.

- Metal foams have a high capacity for absorbing noise energy in a certain amount of pressure.

- Metal foams are more capable in absorbing trauma in the same waves.

Ceramic foams are also a good option for use in high temperatures. These foams are made the same way as polyurethane foams with open cells formed as honeycombs. This foam is usually made from silicon elements; although, they are likely to be made from other ceramic elements such as Zirconium, Titanium and Baron as well. Ceramic foams are 80 to 90 percent porous and can be used in temperatures more than $1500^{\circ} \mathrm{C}$. New ceramic foams have been made from aluminum oxide and have a porous index above $94 \%$. Usually ceramic foams have a wide application in space technology and industry such as making rocket parts, combination panels, thermal protective devices and acoustic lines inside airplane mufflers [32] [33].

Aerosols are another form of tiny porous material used in complicated processes. Aerosols are also called frozen smoke and are used for better thermal isolation. This product is 40 times better than usual fiberglass isolators [4]. Aerosols have a consistent internal structure and consist of porous, light weighted and clear material which their internal volume is filled with air. Several kinds of raw material are used for producing aerosols; however the silica aerosols are more popular. The structure of these materials is from small spherical dioxide silicon material with a diameter between 3 to 4 nanometers [34]. Generally the average size of these pores is between 30 to 40 nanometers. Usually the aerogel pores are above $75 \%$ and their melting temperature is $1200^{\circ} \mathrm{C}$ [4].

Unfortunately, aerogels are still too expensive. These materials were used for the first time in NASA advanced space technology. Meanwhile the application of these materials in the form of granule and for sound absorption has become popular. The results of multilayer absorption panels made from silica aerogel have been announced by many experts [35]. The mean size and density of the pores in the production process is controllable. Usually the size of the combined aerosols is between 5 to 20 nanometers, and the experiments have shown that these materials have better absorbing characteristics in comparison to commercial fiberglass [36]. Progress in the production of these materials is very likely, because the cost of producing aerogels is decreasing. This fact can lead to their wide application in the automobile and construction industry in the near future [4].

\subsection{Porous Asphalt}

Most of the environmental noise is produced by cars and trucks, in high and average speeds, and from the reaction between the road and tires [4] [37]. For automobiles, the sound produced in the A network is between 800 to $1000 \mathrm{~Hz}$. Meanwhile for light and heavy trucks the sound produced in A network is in the frequency range between 800 to $1200 \mathrm{~Hz}$. One way for decreasing noise, is using porous surface covers on roads. These covers are classified as granular absorbing material. The surfaces have advantages, they not only decrease the noise produced by tire road interaction, but also decrease the motor noise of vehicles, in situations such as proximity to residential places by absorbing noise. In case these absorbents get equipped with other facilities such as water or waste water drainage, the noise of water splashed on automobiles will also decrease in heavy rainfall [4]. Noise absorption by porous surfaces is also determined by several geometric parameters. Other parameters related to road surface covers are [4]:

- The thickness of the porous layer;

- The air volume or the porosity of the road;

- The air resistance according to unit of length;

- Curve;

- The size of the particles making up the asphalt density.

For almost all combinations of dense asphalt, the air volume is about $5 \%$. Meanwhile for the combinations of new porous material, the air volume change is about $15 \%$ to $30 \%$. Evaluating the noise absorption characteristic 
of some porous road surfaces for decreasing automobile noise in the intra state highways in Cracker et al.'s study showed that thick porous surfaces had the highest absorption in low frequencies [37].

\subsection{Smart Sound Absorbers}

Recently active noise absorption and passive control have been used for the development of hybrid sound absorbers. Active control technologies have been developed as the only method for noise reduction in low frequencies. Therefore a hybrid active/non active absorber can absorb the clash noise in a wider frequency range. The basis of work of these absorbers is a device with layers of porous material with passive absorbing characteristics combined with an intensifying layer for active control, which can be controlled by using digital techniques [38] [39].

In this study smart foam has been explained as a noise absorbing material in low frequencies and as an active/ passive noise absorber. This absorbent has been made from melamine foam (made from resin melamine and thermal polymer) and inter film stimulators such as PVDF [4].

This compound material provides the possibility of high noise absorption in high and average frequencies which is among the characteristics of passive melamine foam. Although, noise absorption in low frequencies is created by active classic elimination mechanisms, efficient improvement of noise absorption characteristics has been performed by element finite 3-D techniques [40] [41]. Therefore it is possible to produce an efficient noise absorbent which is thin and light weighted. Another type of these equipments consists of a combination of active and passive control by using panel networks. These results have shown hopeful results in absorbing systems [4].

\section{Discussion}

In choosing noise absorbent material in addition to the recognized advantages and the appropriateness of the absorbent for use in the environment, we also have to pay attention to factors related to sound absorption such as fiber size, the resistance of air flow, porosity, curve, thickness and density of absorbents. One important microscopic parameter of a fiber is its diameter. The diameter of a fiber is directly related to its sound absorbing characteristics. Table 1 shows the diameters of several fibers that have been measured by electronic microscopy [4]. Generally the diameter of natural fibers is more than the diameter of artificial fibers which have been achieved through extrusion. Figure 3 shows photos taken by electronic microscopy from the fibers of hemp, kenaf, cotton and polyester. Obviously the natural fibers have more irregular shapes and various diameters in comparison to artificial fibers [42] [43]. Results from Koizumi et al.'s study showed that by decrease in the diameter of fibers, sound absorption increases, therefore in absorbents, small fibers lead to more air resistance because of friction and viscous vibration in the air. Therefore the coefficient of sound absorption increases [23].

Air flow resistance is one of the most important characteristics of sound absorbent fibers in each unit of thickness. This characteristic is defined according to this Formula [44]:
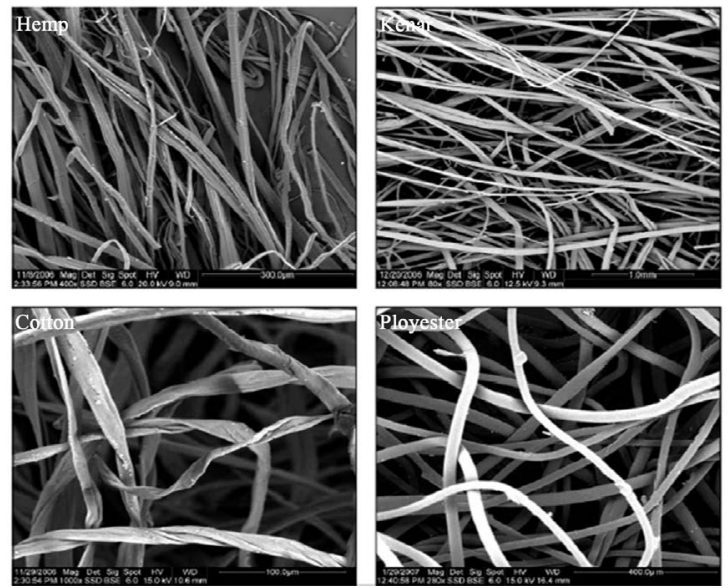

Figure 3. Electronic microscopy images from Hemp, top left (Mag 400×); Kenaf , top right (Mag 80×); Cotton, bottom left (Mag 1000×), Polyester, bottom right (Mag 280×). (taken from Reference 4). 
Table 1. The mean diameter of several industrial absorbent fibers (mainly from Ref 4).

\begin{tabular}{ccc}
\hline Source of material & Type of fiber material & Fiber diameter $(\boldsymbol{\mu m})$ \\
\hline \multirow{2}{*}{ Artificial } & Ceramic & $2-6$ \\
& Mineral wool & $3-10$ \\
& Fiber glass & $6-13$ \\
& Glass wool & $3-7$ \\
& Graphite & $5-10$ \\
& Basalt & $7-13$ \\
& Polypropylene & $5-25$ \\
& Polyester & $3-15$ \\
Natural & Kevlar & 12 \\
& Cotton & $8-33$ \\
& Kenaf & 21 \\
& Hemp & 22 \\
& Wood & $16-38$ \\
& Flax & 19 \\
\hline
\end{tabular}

$$
R_{1}=\frac{\Delta_{p}}{\Delta_{T u}} \mathrm{mks} \cdot \text { Rayls } / \mathrm{m}
$$

In this formula, $\mathrm{R}_{1}$ is the specific flow resistance, $\mathrm{u}$ is the particle speed measured as $\mathrm{m} / \mathrm{s}, \Delta_{p}$ is the sound pressure differentiate all along the measured thickness along the speed path of the particles and $\Delta_{T}$ is the changes in thickness. According to the experiments done on air flow (ASTM D-1564-1971) the air flow resistance is calculated from this formula:

$$
R=\frac{P}{v l}
$$

In this formula $P$ is the difference of statistic pressure between the two surfaces of the sample measured as $d y n / \mathrm{cm}^{2}, V$ is the air flow speed according to $\mathrm{cm} / \mathrm{s}$ and $\mathrm{L}$ is the thickness of the sample according to $\mathrm{cm}$. The air flow resistance in each unit of thickness in porous material is directly related to the shear viscosity coefficient of the fluid (air) and inversely related to the pore size of the material [44]. Porosity is one of the important factors in noise absorption. The porosity of material is defined as the volume of the pore $\left(V_{a}\right)$ in the sample to the total volume of the sample $\left(V_{m}\right)$ [4]. According to this, Alard et al. have suggested this formula for determining the porosity of absorbent material [45]:

$$
\operatorname{Porosity}(H)=\frac{V_{a}}{V_{m}}
$$

When porous material are exposed to sound waves, molecules on the external surface and between the pores absorb the energy, vibrate and therefore some of this energy is lost. This phenomenon occurs due to the conversion of energy to heat after their collision with the absorbing molecules. This heat is produced due to the heat loss and the viscosity inside the inner layers of the pores and tunnels of porous absorbent material. In low frequencies these interactions are isothermal, but in high frequencies the changes are adoptive. In fibrous material, high amounts of energy can be created by the dispersion made by the fibers and also the vibration created in the fibers. Fibers are rubbed against each other due to sound waves [17].

The mechanism of sound absorption in granule mass material is completely similar to solid porous material and its solid structure can present friction because of its appropriate strength and then sound absorption occurs by air viscosities trapped inside the empty and connected spaces inside the granules and separately in each granule. In low and average frequencies the interactions of the solid structure with the gaseous spaces happens through iso- 
thermal heat converting processes. Also, the scattering from the granules is also effective in absorbing sound energy inside these materials. Curve is also an efficient factor for absorbing sound in these materials, and is introduced in the internal structure of material [46]. Some studies have mentioned the determinant role of curve on the behavior of noise absorbing material in high frequencies [44].

Among the other factors effective on noise absorption are the thickness of absorbing material. The results of several studies about noise absorption by porous material showed that noise absorption is directly related to thickness in low frequencies. The rule of the thumb is that noise absorption in porous absorbents happens when the thickness of material is about one tenth of the noise wave. Absorption in conditions where the resonant frequency is a quarter of the sound wave (despite the adaptation effect) in high frequencies has little effect on noise absorption. The density of material is often an important factor on the absorbing properties of sound. Also the cost of acoustic material is directly related to the density. Research done about this topic showed that by increasing density, noise absorption increases in middle and high frequencies [23]. Density increases when the number of fibers increases in the unit of surface. As the number of fibers increase, friction also increases and therefore the loss of energy also increases. Therefore the coefficient of noise absorption increases [44].

There is little information available about the effect of compression. The results of Castagend et al. about the compression of irregular fibers show that sound absorption decreases in these fibers. The authors also discovered the effect of compression on increasing curve and air resistance and decrease in the pores of porous material. Despite the changes in the aforementioned parameters, the main reason is decrease in sound absorption due to compression and decreased thickness [47]. The tolerance of the surface also increases the resistance to absorption, therefore by increase in the reflection of the absorbing surface, the absorption capacity of the absorbing material decreases. Therefore surface resistance is also effective on noise absorption. All of the processes are related to frequency. Therefore for lower frequencies, the thickness of the layers have to increase, and based on this the resistance will also decrease.

The placement or position of sound absorption is a known phenomenon in which according to that sound absorption in material depends on placement and the position of sound absorbing material. If we use several absorbents, each one of them is appropriate for different places such as corners, walls and ceiling. In rectangular places inserting absorbing material close to the corners and the edges of the surface are more efficient. In lecturing studios some of these absorbents which are effective in higher frequencies, should be assembled at human height on the wall. In reality the effect of the assembled absorbents on higher heights of the wall is two times more than other places. Also it is suggested that surfaces that do not have absorbing material should never be placed in front of each other [48].

The efficiency of absorbing material is reported according to the sound absorbing coefficient. The scale of absorption is shown by " $\alpha$ ". The absorption coefficient is the amount of energy absorbed to the total amount of sound energy and the reflection coefficient $(\tau)$ is the amount of reflective energy to the total collision energy of sound. If the absorbing coefficient of material becomes zero, this means that the total amount of collision energy has been reflected and vice versa. If all of the encountered sound gets absorbed, the absorption coefficient of that material will become 1 . A positive amount of $(\tau)$ shows the amount of reflection of the sound wave on the surface of the material. If the amount of $(\tau)$ approaches zero, the energy transfer is very little. Therefore both coefficients have a range between zero and one [14]. When one homogenous layer has the thickness of L, the impedance characteristics of $Z_{c}$ and the dispersion coefficient of $\gamma$ and acoustic impedance based on the other side of the absorbent of $Z_{2}$, the acoustic impedence of the surface of material $\left(Z_{1}\right)$ will be calculated according to this formula [8]:

$$
Z_{1}=Z_{c} \frac{Z_{2} \cos h \gamma L+Z_{c} \sin h \gamma L}{Z_{2} \sin \gamma L+Z_{c} \cos h \gamma L}
$$

Meanwhile the coefficient of sound absorptions is [8]:

$$
\alpha=1-\left|\frac{\left(\frac{Z_{1}}{Z_{\text {air }}}\right)-1}{\left(\frac{Z_{1}}{Z_{\text {air }}}\right)+1}\right|^{2}
$$

Figure 4 shows the comparison between the absorption coefficients of the natural absorbents and artificial 


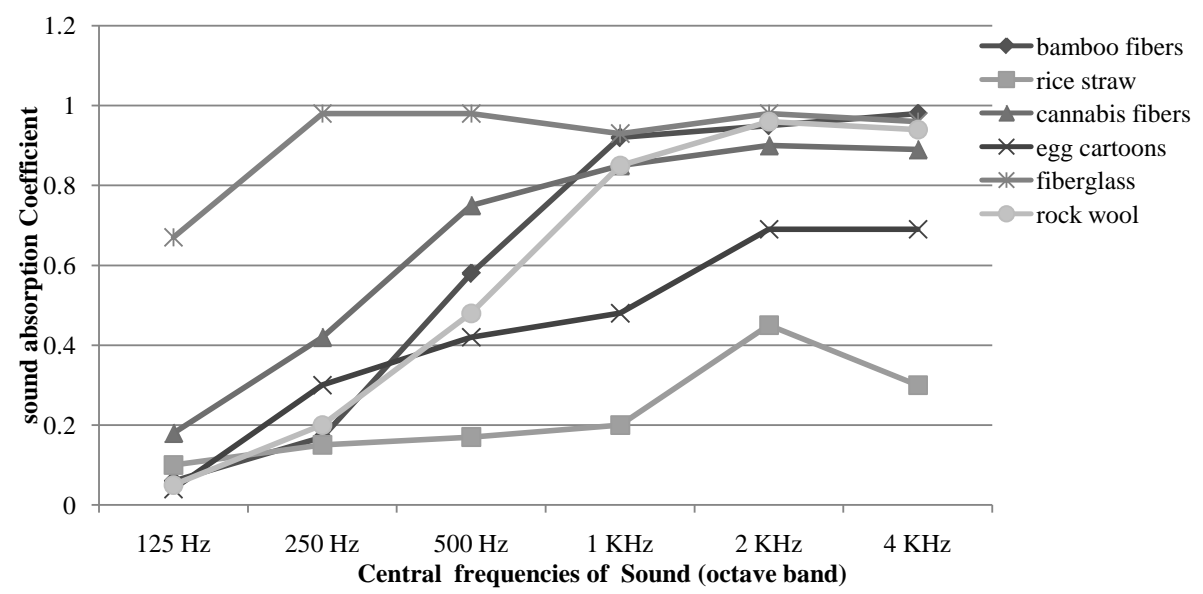

Figure 4. The absorption coefficient of natural absorbents, retrieved from other studies, bamboo fibers (Ref 8), rice straw (Ref 10), cannabis fibers (Ref 4), egg cartoons (Ref 14), and artificial commercial absorbents.

absorbents such as glass wool and stone wool which are commonly used in Iran. As it can be seen it is possible to substitute commercial material with artificial bases; by environmental friendly material; by improving the absorbent factors in natural and recycled material.

\section{Conclusions}

In comparison to old absorbents, new materials are safer and lighter and enjoy a more efficient technology. It seems like environmental friendly, degradable, recyclable and greenly produced noise absorbents will play on important role in the market of noise absorbents in the future. As more researches are done and the production increases, we predict that the number of new noise absorbent material will increase in the next years.

Also because of different places and different uses of absorbent material, specialists should consider the limitations of the environment and the acoustic characteristics of the absorbents. Therefore in choosing absorbent material, effective factors on noise absorption such as size of fibers (in fibrous absorbents), air resistance, porosity, placement or position of sound absorbents, compression, curve, thickness and density of absorbents should be considered.

\section{References}

[1] Rmili, W., Ouahabi, A., Serra, R. and Kious, M. (2009) Tool Wear Monitoring in Turning Processes Using Vibratory Analysis. International Journal of Acoustics and Vibration, 14, 4-11.

[2] Crocker, M.J. (2007) Handbook of Noise and Vibration Control. Wiley, Hoboken. http://dx.doi.org/10.1002/9780470209707

[3] Nahvi, H., Fouladi, M.H. and Nor, M.J.M. (2009) Evaluation of Whole-Body Vibration and Ride Comfort in a Passenger Car. International Journal of Acoustics and Vibration, 14, 143-149.

[4] Arenas, J.P. and Crocker, M.J. (2010) Recent Trends in Porous Sound-Absorbing Materials. Sound \& Vibration, 44, 12-17.

[5] Chavan, A.T. and Manik, D.N. (2008) Optimum Design of Vibro-Acoustic Systems Using SEA. International Journal of Acoustics and Vibration, 13, 67-81.

[6] Asdrubali, F., Ed. (2006) Survey on the Acoustical Properties of New Sustainable Materials for Noise Control. Proceedings of the Euronoise 2006 Conference, 30 May-1 June 2006, Tampere.

[7] Nick, A., Becker, U. and Thoma, W. (2002) Improved Acoustic Behavior of Interior Parts of Renewable Resources in the Automotive Industry. Journal of Polymers and the Environment, 10, 115-118. http://dx.doi.org/10.1023/A:1021124214818

[8] Koizumi, T., Tsujiuchi, N. and Fujita, K., Eds. (2004) Performance Improvement of Sound-Absorbing Materials Using Natural Bamboo Fibers and Their Application. WIT Press Publishing Services, Ashurst.

[9] Zent, A. and Long, J.T. (2007) Automotive Sound Absorbing Material Survey Results. SAE Technical Paper 2007-012186. http://dx.doi.org/10.4271/2007-01-2186 
[10] Yang, H.S., Kim, D.J. and Kim, H.J. (2003) Rice Straw and Wood Particle Composite for Sound Absorbing Wooden Construction Materials. Bioresource Technology, 86, 117-121. http://dx.doi.org/10.1016/S0960-8524(02)00163-3

[11] Zulkifli, R., Zulkarnain, M. and Nor, M.J.M. (2010) Noise Control Using Coconut Coir Fiber Sound Absorber with Porous Layer Backing and Perforated Panel. American Journal of Applied Sciences, 7, 260-264. http://dx.doi.org/10.3844/ajassp.2010.260.264

[12] Ilgun, A., Cogurcu, M.T., Ozdemir, C., Kalipci, E. and Sahinkaya, S. (2010) Determination of Sound Transfer Coefficient of Boron Added Waste Cellulosic and Paper Mixture Panels. Scientific Research and Essays, 5, 1530-1535.

[13] Yang, H.S., Kim, D.J., Lee, Y.K., Kim, H.J., Jeon, J.Y. and Kang, C.W. (2004) Possibility of Using Waste Tire Composites Reinforced with Rice Straw as Construction Materials. Bioresource Technology, 95, 61-65. http://dx.doi.org/10.1016/j.biortech.2004.02.002

[14] Antonio, Q.R., Ed. (2010) Measurement of the Sound-Absorption Coefficient on Egg Cartons Using the Tone Burst Method. World Scientific and Engineering Academy and Society (WSEAS), Stevens Point.

[15] Alamdari, Z.G., Khavanin, A. and Kokabi, M. (2008) Manufacturing Sound Absorber Based on Combined Recycling of Polyethylene Trephetalat and Polystyrene at Low and Median Frequencies. Audiology, 17, 63-69.

[16] Pfretzschner, J. and Rodriguez, R.M. (1999) Acoustic Properties of Rubber Crumbs. Polymer Testing, 18, 81-92. http://dx.doi.org/10.1016/S0142-9418(98)00009-9

[17] Crocker, M.J. and Arenas, J.P. (2007) Use of Sound Absorbing Materials. In: Crocker, M.J., Ed., Handbook of Noise and Vibration Control, John Wiley and Sons, New York, 696-713. http://dx.doi.org/10.1002/9780470209707.ch57

[18] Kazragis, A., Gailius, A. and Juknevi, A. (2002) Thermal and Acoustical Insulating Materials Containing Mineral and Polymeric Binders with Cellulose Fillers. Materials Science, 8, 193-195.

[19] Magrini, U. and Ricciardi, P. (2000) Surface Sound Acoustical Absorption and Application of Panels Composed of Granular Porous Materials. Proceedings of the Inter-Noise, Nice, 27-30 August 2000.

[20] Asdrubali, F. and Horoshenkov, K.V. (2002) The Acoustic Properties of Expanded Clay Granulates. Building Acoustics, 9, 85-98. http://dx.doi.org/10.1260/135101002760164553

[21] Attenborough, K. and Umnova, O. (2005) Chapter 8: Acoustics of Rigid-Porous Materials. In: Wright, M.C.M., Ed., Lecture Notes on the Mathematics of Acoustics, Imperial College Press, London, 157.

[22] Del Rey, R., Alba, J. and Sanch, A.S.V., Eds. (2007) Proposal of an Empirical Model for Absorbent Acoustical Materials Based in Kenaf. Proceedings of the 19th International Congress on Acoustics, Madrid, 2-7 September 2007, 3361-3366.

[23] Koizumi, T., Ed. (2002) The Development of Sound Absorbing Materials Using Natural Bamboo Fibers and Their Acoustic Properties. Proceedings of the Inter-Noise, Dearborn, 19-21 August 2002.

[24] Zulkifh, R., Nor, M.J.M., Tahir, M.F.M., Ismail, A.R. and Nuawi, M.Z. (2008) Acoustic Properties of Multi-Layer Coir Fibres Sound Absorption Panel. Journal of Applied Sciences, 8, 3709-3714. http://dx.doi.org/10.3923/jas.2008.3709.3714

[25] Ashby, M.F. and Lu, T. (2003) Metal Foams: A Survey. Science in China Series B: Chemistry, 46, 521-532. http://dx.doi.org/10.1360/02yb0203

[26] Hao, G.L., Xu, Q.P., Han, F.S., Li, W.D. and Bai, S.M. (2009) Processing and Damping Behaviour of Porous Copper. Powder Metallurgy, 52, 145-150. http://dx.doi.org/10.1179/003258908X356885

[27] Jiejun, W., Chenggong, L., Dianbin, W. and Manchang, G. (2003) Damping and Sound Absorption Properties of Particle Reinforced Al Matrix Composite Foams. Composites Science and Technology, 63, 569-574. http://dx.doi.org/10.1016/S0266-3538(02)00215-4

[28] Miyoshi, T., Itoh, M., Akiyama, S. and Kitahara, A. (2000) ALPORAS Aluminum Foam: Production Process, Properties, and Applications. Advanced Engineering Materials, 2, 179-183. http://dx.doi.org/10.1002/(SICI)1527-2648(200004)2:4<179::AID-ADEM179>3.0.CO;2-G

[29] Banhart, J. (2001) Manufacture, Characterisation and Application of Cellular Metals and Metal Foams. Progress in Materials Science, 46, 559-632. http://dx.doi.org/10.1016/S0079-6425(00)00002-5

[30] Lu, T.J., Hess, A. and Ashby, M.F. (1999) Sound Absorption in Metallic Foams. Journal of Applied Physics, 85, 7528. http://dx.doi.org/10.1063/1.370550

[31] Tang, H.P., Zhu, J.L., Wang, J.Y., Ge, Y. and Li, C., Eds. (2008) Sound Absorption Characters of Metal Fibrous Porous Material. DEStech Publications, Inc., Lancaster.

[32] Wu, X., Chen, Z.H., Feng, Y.L., Liu, X.P. and Li, X.L. (2011) Fabrication of Micro-Honeycomb Ceramics by Cloth Fabric Pore-Forming. Transactions of Nonferrous Metals Society of China, 21, 2665-2670.

http://dx.doi.org/10.1016/S1003-6326(11)61108-4 
[33] Scheffler, M. and Colombo, P. (2005) Cellular Ceramics: Structure, Manufacturing, Properties and Applications. WILEY-VCH Verlag GmbH \& Co. KGaA, Weinheim.

[34] Schmidt, M. and Schwertfeger, F. (1998) Applications for Silica Aerogel Products. Journal of Non-Crystalline Solids, 225, 364-368. http://dx.doi.org/10.1016/S0022-3093(98)00054-4

[35] Ricciardi, P., Gibiat, V. and Hooley, A., Eds. (2002) Multilayer absorbers of silica aerogel; 2002.

[36] Dong, W., Faltens, T., Pantell, M., Simon, D. and Thompson, T., Eds. (2009) Acoustic Properties of Organic/Inorganic Composite Aerogels. Cambridge University Press, Cambridge.

[37] Crocker, M.J., Li, Z. and Arenas, J.P. (2005) Measurements of Tyre/Road Noise and of Acoustical Properties of Porous Road Surfaces. International Journal of Acoustics and Vibration, 10, 52-60.

[38] Furstoss, M., Thenail, D. and Galland, M.A. (1997) Surface Impedance Control for Sound Absorption: Direct and Hybrid Passive/Active Strategies. Journal of Sound and Vibration, 203, 219-236. http://dx.doi.org/10.1006/jsvi.1996.0905

[39] Galland, M.A., Mazeaud, B. and Sellen, N. (2005) Hybrid Passive/Active Absorbers for Flow Ducts. Applied Acoustics, 66, 691-708. http://dx.doi.org/10.1016/j.apacoust.2004.09.007

[40] Leroy, P., Berry, A., Attala, N. and Herzog, P. (2008) "Smart Foams” for Enhancing Acoustic Absorption. Proceedings of the Acoustics' 08 Conference, Paris, 29 June-4 July 2008.

[41] Leroy, P., Atalla, N., Berry, A. and Herzog, P. (2009) Three Dimensional Finite Element Modeling of Smart Foam. The Journal of the Acoustical Society of America, 126, 2873-2885. http://dx.doi.org/10.1121/1.3238241

[42] Tascan, M. and Vaughn, E.A. (2008) Effects of Fiber Denier, Fiber Cross-Sectional Shape and Fabric Density on Acoustical Behavior of Vertically Lapped Nonwoven Fabrics. Journal of Engineering Fibers and Films, 3, 32-38.

[43] Tascan, M. and Vaughn, E.A. (2008) Effects of Total Surface Area and Fabric Density on the Acoustical Behavior of Needlepunched Nonwoven Fabrics. Textile Research Journal, 78, 289-296. http://dx.doi.org/10.1177/0040517507084283

[44] Seddeq, H.S. (2009) Factors Influencing Acoustic Performance of Sound Absorptive Materials. Australian Journal of Basic and Applied Sciences, 3, 4610-4617.

[45] Allard, J.F., Depollier, C. and Guignouard, P. (1989) Free Field Surface Impedance Measurements of Sound-Absorbing Materials with Surface Coatings. Applied Acoustics, 26, 199-207. http://dx.doi.org/10.1016/0003-682X(89)90053-4

[46] Knapen, E., Lanoye, R., Vermeir, G., Lauriks, W. and Van Gemert, D., Eds. (2004) Sound Absorption by Polymer-Modified Porouscement Mortars. Aedificatio Publishers, Freiburg.

[47] Castagnede, B., Aknine, A., Brouard, B. and Tarnow, V. (2000) Effects of Compression on the Sound Absorption of Fibrous Materials. Applied Acoustics, 61, 173-182. http://dx.doi.org/10.1016/S0003-682X(00)00003-7

[48] Alton, F. (2001) The Master Handbook of Acoustics. McGraw-Hill, New York. 